\title{
Maternal work hours in early to middle childhood link to later adolescent diet quality
}

\author{
Jianghong $\mathrm{Li}^{1,2, *}$, Therese O'Sullivan ${ }^{2,3}$, Sarah Johnson ${ }^{1,2}$, Fiona Stanley ${ }^{2}$ and \\ Wendy Oddy ${ }^{2}$ \\ ${ }^{1}$ Curtin Health Innovation Research Institute, Centre for Population Health Research, Curtin University, Perth, \\ Western Australia, Australia: ${ }^{2}$ Telethon Institute for Child Health Research, Centre for Child Health Research, \\ The University of Western Australia, 100 Roberts Road, Subiaco, Western Australia 6008, Australia: \\ ${ }^{3}$ School of Exercise and Health Science, Edith Cowan University, Joondalup, Western Australia, Australia
}

Submitted 11 January 2011: Accepted 25 October 2011: First published online 29 November 2011

\begin{abstract}
Objective: Previous studies on maternal work hours and child diet quality have reported conflicting findings possibly due to differences in study design, lack of a comprehensive measure of diet quality and differing ages of the children under investigation. The present study aimed to prospectively examine the impact of parental work hours from age 1 year to age 14 years on adolescent diet quality. Design: Multivariate linear regression models were used to examine independent associations between parents' work hours at each follow-up and across 14 years and adolescent diet quality at age 14 years. A diet quality index was based on the international literature and Australian recommendations, consisting of six food groups and nine nutrients.

Setting: Perth, Western Australia.

Subjects: Children ( $n$ 1629) participating in the Western Australian Pregnancy Cohort (Raine) Study.

Results: Compared with children of mothers in full-time employment, children of mothers who were not employed in early childhood up to age 5 years had a higher average diet quality score at age 14 years, independent of maternal and family socio-economic status. Across 14 years the number of years the mother worked full time and increasing average weekly hours were associated with lower diet quality. Father's work hours had little association with adolescent diet quality. Conclusions: Having a mother stay at home in early to middle childhood is associated with better diet quality in adolescence. Support may be beneficial for families where the mother returns to full-time employment before the child reaches 8 years of age.
\end{abstract}

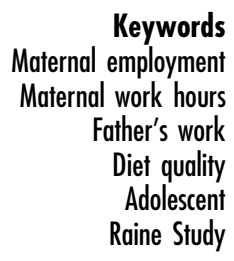

Over the last few decades, the traditional family model of a mother involved in full-time home duties and the father as the breadwinner has changed. In Australia and many Western countries, social and economic changes since the 1980s have resulted in an increased number of mothers in the paid labour force. Between 1984 and 2009, the proportion of Australian mothers with dependant children in paid employment increased from $43 \%$ to $63 \%$. Within this 25 -year period, the proportion of mothers in couples with young children ( $0-4$ years) in paid employment increased from $30 \%$ to $52 \%$; the increase was smaller among lone mothers with young children, from $19 \%$ to $27 \%{ }^{(1)}$. While mothers' employment or long work hours can increase family income, it may also reduce their capacity to provide adequate time for children to develop healthy eating patterns, an integral part of their development.
Mothers are usually responsible for food shopping and meal preparation ${ }^{(2)}$, hence it is important to investigate whether increasing maternal work hours affect the dietary quality of children. Despite a number of previous studies on maternal employment and child nutrition ${ }^{(3-8)}$, relatively little is known about differences in robust measures of children's dietary quality by parental employment status. Extra household income generated from maternal employment allows the family to afford a wider variety of better-quality groceries and fresh produce, but working mothers may have less time or energy to plan, shop or prepare healthy meals, and as a result more meals may be purchased from restaurants or fast-food outlets ${ }^{(9-11)}$.

Previous studies investigating parental employment and diet in children and adolescents have reported conflicting results. Some have shown positive associations 
between maternal employment and nutrition ${ }^{(3,4,12)}$, others negative ${ }^{(5,6)}$, and others have shown none ${ }^{(7,8)}$. This variability may be related to differences in the age of the children under investigation (ages 2 to 18 years), how parents' work was measured (working $v$. not working, part time or full time or long work hours), whether or not potential confounding variables were adjusted for (e.g. parental education and family income), the crosssectional design ${ }^{(4,6,7,12)}$ and economic environment (e.g. developed $^{(5-8,12)} v$. developing countries $\left.{ }^{(3,4)}\right)$. Varying methods of assessing dietary quality or pattern may also have contributed to conflicting findings in previous studies. Some have used intake of selected individual nutrients ${ }^{(4)}$, some meal patterns ${ }^{(8,13)}$ and others questions investigating dietary habits such as meal skipping or intake of soft drinks ${ }^{(3,14)}$. Using these types of assessment to measure dietary quality may be limiting as they only consider a small number of nutrients or isolated aspects of the diet. An alternative method is to use a quality index score which represents a broader picture of food and nutrient consumption and thus considers the diet as a whole ${ }^{(15)}$.

Few studies have examined the link between child dietary quality and parental work from a longitudinal perspective $^{(5,16)}$. It is possible that children develop healthy dietary habits in infancy and early to middle childhood and this development may continue into adolescence. Dietary pattern in adolescence is likely to reflect the early onset of the ongoing development of healthy eating in children. Most previous studies have not examined the potential influence of fathers' work on child diet quality. While mothers often assume the responsibility of food shopping and meal preparation ${ }^{(2)}$ and hence have a greater influence on children's diet quality, fathers can also play a role in developing and maintaining healthy diet in the family. Fathers who work part time may be more likely than fathers who work long hours to assist with meal preparation or other housework and child care, so that mothers can devote adequate time for healthy meal provision. Fathers may also take more responsibility for preparing school lunches and afterschool snacks, shopping and preparing meals when mothers work full-time hours. Bauer and co-authors ${ }^{(16)}$ have shown that father's employment when the child was in middle school was associated with higher odds of the adolescent consuming fast food in high school but father's concern with healthy eating was associated with lower odds of fast-food intake in high school in the USA.

To date no studies have investigated parental work and adolescent diet prospectively, using a diet quality index. The present study aimed to investigate the association between both mother's and father's involvement in the work force from age 1 year to age 14 years and a dietary quality index measured at age 14 years in a cohort of adolescents in Western Australia, independent of maternal age, race and education, family income, family structure, child gender and the number of siblings.

\section{Methods}

\section{Participants}

The Western Australian Pregnancy Cohort (Raine) Study recruited 2900 mothers between the 16th and 20th week of gestation from May 1989 to November 1991 and the initial cohort comprised 2868 live births. The study methods are reported elsewhere ${ }^{(17)}$. The Human Ethics Committees at King Edward Memorial Hospital and/or Princess Margaret Hospital for Children in Perth approved all protocols for the study.

In brief, data were collected at ages 1 year and 2, 3, 5, 8,10 and 14 years (overall response rate of $76 \%$ ). The 14-year follow-up commenced in 2003, as close to the participants' 14th birthday as possible, and was completed in 2006. Data collection included anthropometry, physical activity, cardiovascular functioning and dietary intake. At 14 years 1860 participants completed all or part of the follow-up, 357 deferred their participation until the next follow-up, 207 were lost to follow-up, 412 withdrew from the Raine Study and thirty-two had died. The current substudy was based on 1629 (87.6\% of 1860) participants who completed an FFQ at the 14-year follow-up.

\section{Diet quality}

The adolescents' usual dietary intake over the previous 12 months was assessed with a semi-quantitative FFQ developed by the Commonwealth Scientific and Industrial Research Organisation (CSIRO) in Adelaide, Australia ${ }^{(9,10)}$. The FFQ was completed by the primary caregiver in consultation with the study adolescent. Respondents were asked about their usual consumption of 212 food and beverage items, excluding alcohol, and how their usual serving compared with a standard serving size given in household measurements (spoons, cups, slices, etc.). All completed FFQ were checked by a research nurse and missing or unclear responses were clarified when the adolescents attended their physical assessment. The CSIRO entered and verified the FFQ and provided estimates of daily intakes of foods and nutrients using Australian food composition data. This FFQ has been shown to correctly rank a reasonable proportion of most nutrient intakes when compared with a $3 \mathrm{~d}$ food record in this cohort ${ }^{(18)}$.

Based on the international literature and Australian recommendations ${ }^{(19)}$, we compiled an index of diet quality consisting of fifteen components including six food groups and nine nutrients. The food groups were: (i) breads, cereals, rice, pasta and noodles; (ii) vegetables; (iii) fruit; (iv) milk, yoghurt and cheese; (v) meat, fish, poultry, eggs, nuts and legumes; and (vi) extra foods (takeaway food, cakes, chips, biscuits, sweets, soft drinks) ${ }^{(19)}$. The nutrients included key nutrients from the respective food groups: (i) vitamin C; (ii) vitamin A (retinol); (iii) dietary fibre; (iv) $\mathrm{Fe}$; (v) $\mathrm{Ca}$; (vi) protein; (vii) total fat as a percentage of total kilojoules; (viii) saturated fat as a percentage of 
total kilojoules; and (ix) the $n-6: n-3$ fatty acid ratio (omega-6:omega-3). We utilized a scoring system based on the Australian Guide to Healthy Eating ${ }^{(19)}$ and Nutrient Reference Values for Australia and New Zealand ${ }^{(20)}$. The maximum score was 150 being indicative of the highest dietary quality whereas the minimum score was 20 indicative of the lowest dietary quality.

\section{Parental work}

Data on mother's working hours were collected at all follow-ups and coded as not working, working 1-15 h, $16-24 \mathrm{~h}, 25-34 \mathrm{~h}$ or $\geq 35 \mathrm{~h}$ (full time) weekly. Father's work hour data were collected at ages 5, 8, 10 and 14 years, and coded as not working, working 1-34h, $35-44 \mathrm{~h}, 45-54 \mathrm{~h}$ or $\geq 55 \mathrm{~h}$ weekly. At ages 1,2 and 3 years, only father's employment status was collected (employed or not). Further, joint employment in couple families was analysed from age 1 year to age 14 years and coded as: (i) neither parent working; (ii) mother working part time or full time/father not working; (iii) mother working full time/father working; (iv) mother working part time/father working; or (v) mother not working/ father working. To examine the overall effects of both parents' work hours during the entire period and at five stages of development (from age 1 year to ages 3, 5, 8, 10 and 14 years), we constructed three sets of continuous variables: (i) the average hours the mother worked per week; (ii) the number of years the mother worked full time and part time; and (iii) the average of hours and the number of years the father worked for $\geq 45 \mathrm{~h}$ weekly (from ages 5 to 14 years due to lack of data on father's working hours in the first three years).

\section{Potential confounders}

Parental education ${ }^{(6,21)}$, particularly mother's education ${ }^{(22-24)}$, family income ${ }^{(25-27)}$, maternal age ${ }^{(22)}$ and ethnicity/race ${ }^{(16)}$ have been linked to children's diet quality and these factors are also associated with parental employment status and work patterns. To control for these potential confounders, we included in the subsequent multivariate analyses: maternal age at pregnancy $(<20,20-24,25-29$, $30-34$, $\geq 35$ years), maternal race (Caucasian or other), mother's education (primary schooling only, trade certificate/other qualification, college diploma, professional degree, university degree), family structure (couple-both biological parents, couple-step parent, lone parent) at each follow-up and combined annual family income at age 14 years ( $<$ \$AUD 25000, \$AUD 25 000-35000, \$AUD 35001-50 000, \$AUD 50 0001-70 000; \$AUD 70 001-140 000, $>$ \$AUD 140000). We also adjusted the analyses for child gender and the number of siblings in the household at the time of pregnancy.

\section{Analysis}

The diet quality index in adolescence at age 14 years was examined, using cross-sectional information on parental work at age 14 years and longitudinal data on parental work prior to age 14 years (from age 1 to 3 years, ages 5 , 8 and 10 years) in a series of multivariate regression models. We first analysed all types of families using only mother's work hours as the main independent variables. We then examined father's and mother's work hours simultaneously in two-parent families, including couple families with a step parent. Parents' work hours were analysed as categorical rather than continuous variables to differentiate various parttime or full-time working hours. We conducted the $F$ test for overall differences with four degrees of freedom, as well as tests for differences between categories of work hours in the diet quality index at age 14 years. In a further step we examined the cumulative effects of mother's and father's work hours on adolescent diet quality at age 14 years, using the average work hours across the follow-ups, the number of years the mother worked full time or part time, and the father worked extended hours, as described above. Analyses were accomplished using multivariate general linear regression models in the SPSS statistical software package version 16 (SPSS Inc., Chicago, IL, USA). A $P$ value of $\leq 0 \cdot 05$ was considered as statistically significant.

\section{Results}

Table 1 shows the frequency distribution of the diet quality index in 1629 adolescents for whom the dietary data were collected at age 14 years. The index score has a near normal distribution, with a mean of $76 \cdot 1$, a standard deviation of 15.51, a minimum and a maximum score of 20 and 120 respectively (Table 1 ). Thus a linear regression model was appropriate for analysing the diet quality index as the outcome variable. Table 1 also shows the maternal and family socio-economic characteristics of the study population.

At ages 1 and 2 years, between $64.8 \%$ and $67.0 \%$ of mothers in all families were not working but this proportion began to decrease from age 3 years onwards, to only $23.3 \%$ by age 14 years (Table 2 ). The percentage of mothers who worked full time ( $\geq 35 \mathrm{~h}$ weekly) increased from $7 \cdot 9 \%$ at age 1 year to $25 \cdot 1 \%$ at age 14 years. Independent of maternal age, race, education, family income, family structure, child gender and number of siblings, there was a significant overall association between mother's work hours when the child was aged 1 year and the diet quality score at age 14 years. Compared with children whose mothers worked full time, those children whose mothers either did not work or worked only part time had a higher average diet quality index score, with a difference ranging from 4.76 to 9.55 points. At ages 2, 3 and 5 years, there remained a significant global association between maternal work hours and diet quality as indicated in the $F$-test statistics. More specifically, having a mother not working, compared with working full time, continued to be positively associated with the diet quality score at age 14 years, with the effect size declining at age 5 years. 
Table 1 Maternal and family socio-economic and demographic characteristics of the study population $(n 1629)^{\star}$, the Western Australian Pregnancy Cohort (Raine) Study

\begin{tabular}{|c|c|c|c|c|c|c|}
\hline Variable name & $n$ & $\%$ & Mean & SD & Min & Max \\
\hline Diet quality index scoret & & & $76 \cdot 08$ & $15 \cdot 51$ & 20 & 120 \\
\hline \multicolumn{7}{|l|}{ Maternal age at birth (years) } \\
\hline$<20$ & 100 & $6 \cdot 1$ & & & & \\
\hline $20-24$ & 284 & $17 \cdot 4$ & & & & \\
\hline $25-29$ & 488 & $30 \cdot 0$ & & & & \\
\hline $30-34$ & 480 & $29 \cdot 5$ & & & & \\
\hline$\geq 35$ & 256 & $15 \cdot 7$ & & & & \\
\hline \multicolumn{7}{|l|}{ Maternal race } \\
\hline Caucasian & 1464 & $89 \cdot 9$ & & & & \\
\hline Other & 144 & $8 \cdot 9$ & & & & \\
\hline \multicolumn{7}{|l|}{ Mother's education in pregnancy } \\
\hline Primary schooling & 733 & $45 \cdot 0$ & & & & \\
\hline Trade/other & 223 & $13 \cdot 7$ & & & & \\
\hline College diploma & 298 & $18 \cdot 3$ & & & & \\
\hline Professional registration/University degree & 375 & $23 \cdot 0$ & & & & \\
\hline \multicolumn{7}{|l|}{ Mother's education at age 8 years } \\
\hline Primary schooling & 638 & $39 \cdot 2$ & & & & \\
\hline Trade/other & 59 & $3 \cdot 6$ & & & & \\
\hline College diploma & 482 & $29 \cdot 6$ & & & & \\
\hline Professional registration/University degree & 365 & $22 \cdot 4$ & & & & \\
\hline \multicolumn{7}{|l|}{ Family structure at age 14 years } \\
\hline Couple-both biological parents & 1060 & $65 \cdot 1$ & & & & \\
\hline Couple-step parent & 205 & $12 \cdot 6$ & & & & \\
\hline Lone parent & 357 & $21 \cdot 9$ & & & & \\
\hline \multicolumn{7}{|c|}{ Combined annual family income at age 14 years (\$AUD) } \\
\hline$<25000$ & 295 & $18 \cdot 1$ & & & & \\
\hline $25000-35000$ & 165 & $10 \cdot 1$ & & & & \\
\hline $35001-50000$ & 327 & $20 \cdot 1$ & & & & \\
\hline $50001-70000$ & 271 & $16 \cdot 6$ & & & & \\
\hline $70001-140000$ & 227 & $13 \cdot 9$ & & & & \\
\hline$>140000$ & 289 & $17 \cdot 7$ & & & & \\
\hline Child gender (male) & 834 & $51 \cdot 3$ & & & & \\
\hline \multicolumn{7}{|l|}{ Number of siblings in pregnancy } \\
\hline 0 & 792 & $48 \cdot 6$ & & & & \\
\hline 1 & 495 & $30 \cdot 4$ & & & & \\
\hline$\geq 2$ & 341 & $20 \cdot 9$ & & & & \\
\hline
\end{tabular}

*Missing cases: maternal age and race (1.3\%), maternal education measured in pregnancy $(0 \%)$, maternal education at age 8 years $(5 \cdot 2 \%)$, family structure $(0.4 \%)$, family income at age 14 years $(3.4 \%)$, child gender $(0.1 \%)$.

tA higher index score represents a better diet quality.

At ages 8 and 14 years, there was no significant overall association between mother's working hours and adolescent diet quality. There was a significant global association between mother's work hours at age 10 years and adolescent diet quality at age 14 years: adolescents whose parents worked a low number of hours $(<25 \mathrm{~h} /$ week $)$ had better diet quality than those whose parents worked full time. However, when mothers worked a moderate number of hours (25-34 h/week), the diet quality was worse, compared with when mothers worked full time.

We observed a similar pattern with maternal employment when father's employment status and work hours were included in the analysis (Table 3). There was a significant global association between mother's working hours (at ages 1, 2 and 3 years) and the diet quality score at age 14 years. Adolescents whose mothers did not work in the first three years of the child's life had a higher than average diet quality score, compared with those whose mothers worked full time in these years. Mother's parttime hours when her child was aged 1 year and short working hours (1-15 h weekly) at age 3 years were also significantly associated with a higher mean diet quality score. From age 5 years onwards, there was no longer a significant global association between mother's working hours and diet quality, and the effect size for not working as indicated by the $\beta$ coefficient declined steadily.

In contrast, father's employment status and work hours had no significant effect on adolescent diet quality in any follow-ups, as indicated by the $P$ values for the global $F$ tests. The increment in the $R^{2}$ when father's work hours were added to the model was small, ranging from an increase of $1 \cdot 8 \%$ to $13 \cdot 7 \%$.

We observed significant global associations between joint parental employment status when the child was 1, 2 and 3 years old and the diet quality scores at age 14 years (Table 4). Having a mother not working with a father working was associated with a higher average diet quality score at age 14 years, compared with when the mother worked full time and the father worked. Maternal parttime work with the father working at age 1 year and age 3 years was also beneficial for diet quality at age 14 years. However, from age 5 to 10 years, there was no longer a 
Table 2 Independent association between maternal working hours and diet quality at 14 years of age: all families $(n 1212 \text { to } 1452)^{\star}$, the Western Australian Pregnancy Cohort (Raine) Study

\begin{tabular}{|c|c|c|c|c|c|c|c|}
\hline \multirow[b]{3}{*}{ Mother's work hours (weekly) } & \multicolumn{7}{|c|}{ Diet quality index } \\
\hline & \multirow[b]{2}{*}{$n$} & \multirow[b]{2}{*}{$\%$} & \multirow[b]{2}{*}{$\beta \dagger$} & \multirow[b]{2}{*}{$P$ value } & \multirow[b]{2}{*}{$F$ test $(\mathrm{df}=4) \ddagger$} & \multicolumn{2}{|c|}{$95 \% \mathrm{Cl}$} \\
\hline & & & & & & Lower & Upper \\
\hline \multicolumn{8}{|l|}{ Age 1 year } \\
\hline Not working & 985 & $64 \cdot 8$ & $5 \cdot 33$ & 0.001 & $P=0.002$ & $2 \cdot 32$ & 8.33 \\
\hline $1-15 \mathrm{~h}$ & 225 & $14 \cdot 8$ & $4 \cdot 80$ & 0.007 & $F=4 \cdot 23$ & $1 \cdot 34$ & $8 \cdot 26$ \\
\hline $16-24 h$ & 139 & $9 \cdot 2$ & $4 \cdot 76$ & 0.01 & & 0.96 & $8 \cdot 55$ \\
\hline $25-34 \mathrm{~h}$ & 50 & $3 \cdot 3$ & $9 \cdot 55$ & $<0.001$ & & $4 \cdot 38$ & $14 \cdot 71$ \\
\hline$\geq 35$ h (ref.) & 120 & $7 \cdot 9$ & & & & & \\
\hline \multicolumn{8}{|l|}{ Age 2 years } \\
\hline Not working & 842 & $67 \cdot 0$ & $4 \cdot 47$ & 0.008 & $P=0.01$ & $1 \cdot 16$ & $7 \cdot 79$ \\
\hline $1-15 h$ & 173 & $13 \cdot 8$ & $2 \cdot 28$ & 0.25 & $F=3 \cdot 31$ & $-1 \cdot 58$ & $6 \cdot 15$ \\
\hline $16-24 \mathrm{~h}$ & 113 & $9 \cdot 0$ & 0.96 & 0.65 & & $-3 \cdot 32$ & $5 \cdot 15$ \\
\hline $25-34 \mathrm{~h}$ & 32 & $2 \cdot 5$ & -0.31 & 0.92 & & $-6 \cdot 51$ & $5 \cdot 90$ \\
\hline$\geq 35 \mathrm{~h}$ (ref.) & 97 & $7 \cdot 7$ & & & & & \\
\hline \multicolumn{8}{|l|}{ Age 3 years } \\
\hline Not working & 889 & $62 \cdot 3$ & $5 \cdot 81$ & $<0.001$ & $P<0.001$ & $2 \cdot 80$ & $8 \cdot 83$ \\
\hline $1-15 h$ & 206 & $14 \cdot 4$ & $2 \cdot 77$ & 0.12 & $F=5.60$ & -0.73 & $6 \cdot 27$ \\
\hline $16-24 \mathrm{~h}$ & 142 & $10 \cdot 0$ & $2 \cdot 56$ & $0 \cdot 18$ & & $-1 \cdot 22$ & $6 \cdot 34$ \\
\hline $25-34 \mathrm{~h}$ & 71 & $5 \cdot 0$ & $1 \cdot 25$ & 0.59 & & -3.29 & $5 \cdot 80$ \\
\hline$\geq 35 \mathrm{~h}$ (ref.) & 119 & $8 \cdot 3$ & & & & & \\
\hline \multicolumn{8}{|l|}{ Age 5 years } \\
\hline Not working & 761 & $50 \cdot 9$ & $2 \cdot 63$ & 0.05 & $P=0.01$ & 0.05 & $5 \cdot 20$ \\
\hline $1-15 h$ & 221 & $14 \cdot 8$ & $3 \cdot 48$ & 0.03 & $F=3 \cdot 14$ & 0.42 & $6 \cdot 54$ \\
\hline $16-24 h$ & 209 & $14 \cdot 0$ & -0.65 & 0.68 & & $-3 \cdot 76$ & $2 \cdot 45$ \\
\hline $25-34 \mathrm{~h}$ & 120 & $8 \cdot 0$ & 0.70 & $0 \cdot 71$ & & $-2 \cdot 92$ & $4 \cdot 31$ \\
\hline$\geq 35$ h (ref.) & 184 & $12 \cdot 3$ & & & & & \\
\hline \multicolumn{8}{|l|}{ Age 8 years } \\
\hline Not working & 658 & $44 \cdot 2$ & $2 \cdot 78$ & & $P=0 \cdot 13$ & 0.29 & $5 \cdot 28$ \\
\hline $1-15 h$ & 234 & $15 \cdot 7$ & $3 \cdot 32$ & & $F=1 \cdot 79$ & 0.36 & $6 \cdot 28$ \\
\hline $16-24 \mathrm{~h}$ & 223 & $15 \cdot 0$ & $1 \cdot 27$ & & & $-1 \cdot 70$ & $4 \cdot 24$ \\
\hline $25-34 \mathrm{~h}$ & 165 & $11 \cdot 1$ & 3.00 & & & -0.21 & $6 \cdot 21$ \\
\hline$\geq 35 \mathrm{~h}$ (ref.) & 210 & $14 \cdot 1$ & & & & & \\
\hline \multicolumn{8}{|l|}{ Age 10 years } \\
\hline Not working & 490 & $32 \cdot 6$ & $2 \cdot 17$ & 0.09 & $P=0.03$ & -0.32 & $4 \cdot 69$ \\
\hline $1-15 \mathrm{~h}$ & 279 & $18 \cdot 6$ & $2 \cdot 06$ & $0 \cdot 14$ & $F=2 \cdot 61$ & -0.68 & $4 \cdot 80$ \\
\hline $16-24 \mathrm{~h}$ & 260 & $17 \cdot 3$ & 2.03 & $0 \cdot 15$ & & -0.75 & $4 \cdot 81$ \\
\hline $25-34 \mathrm{~h}$ & 218 & $14 \cdot 5$ & $-1 \cdot 46$ & 0.33 & & $-4 \cdot 36$ & $1 \cdot 44$ \\
\hline$\geq 35$ h (ref.) & 257 & $17 \cdot 1$ & & & & & \\
\hline \multicolumn{8}{|l|}{ Age 14 years } \\
\hline Not working & 366 & $23 \cdot 3$ & $1 \cdot 27$ & & $P=0 \cdot 11$ & $-1 \cdot 18$ & $3 \cdot 72$ \\
\hline $1-15 \mathrm{~h}$ & 247 & $15 \cdot 7$ & $3 \cdot 30$ & & $F=1.90$ & $0 \cdot 70$ & $5 \cdot 90$ \\
\hline $16-24 h$ & 268 & $17 \cdot 1$ & $2 \cdot 45$ & & & -0.02 & 4.92 \\
\hline $25-34 \mathrm{~h}$ & 294 & $18 \cdot 7$ & $1 \cdot 17$ & & & $-1 \cdot 23$ & $3 \cdot 56$ \\
\hline$\geq 35 \mathrm{~h}$ (ref.) & 394 & $25 \cdot 1$ & & & & & \\
\hline
\end{tabular}

ref., referent category.

*All models adjusted for mother's age, education and race, family income at age 14 years, age-specific family structure, child gender and number of siblings. Mother's education at age 8 years was adjusted for at ages 8,10 and 14 years.

tDifference in the mean of diet quality score between a category of work hours and the reference group. A higher index score represents a better quality diet. $\ddagger$ The global $F$-test statistics for overall differences in diet quality index associated with mother's work hours.

significant overall association between joint parental employment and the diet quality score at age 14 years, and the $\beta$ coefficients for the four categories of joint employment indicated a general decline in the effect size.

At age 14 years, there was a significant overall association between joint employment and the diet quality score and this was mainly reflected in a higher average diet quality score when neither parent worked, compared with the reference group. Having neither parent working in the first three years of the child's life was also associated with a better adolescent diet. However, at any age, when a mother worked but the father did not, there was no improvement in the diet quality score.
Table 5 presents the long-term association between mother's and father's working hours during the growth of the child and adolescent diet quality, independent of maternal age, race and education, family structure, family income, child gender and the number of siblings. The average working hours weekly and the number of years for which the mother worked full time were negatively associated with adolescent diet quality and this association appeared to be stronger in the first eight years of the child's life. Mother's cumulative hours spent in part-time work had no significant effect on the outcome variable. Consistent with the results from Tables 2 to 4 , the number of years the father worked for $\geq 45 \mathrm{~h}$ weekly and the 
Table 3 Independent association between mother's and father's work hours and diet quality at 14 years of age: both-parent families ( $n 1073$ to 1295$)^{\star}$, the Western Australian Pregnancy Cohort (Raine) Study

\begin{tabular}{|c|c|c|c|c|c|c|c|c|c|c|c|}
\hline \multirow{3}{*}{$\begin{array}{l}\text { Mother's work } \\
\text { hours (weekly) }\end{array}$} & \multicolumn{11}{|c|}{ Diet quality index } \\
\hline & \multirow[b]{2}{*}{$\%+$} & \multirow[b]{2}{*}{$\beta \ddagger$} & \multirow{2}{*}{$\begin{array}{c}P \text { value } \\
(\mathrm{df}=4)\end{array}$} & \multicolumn{2}{|c|}{$95 \% \mathrm{Cl}$} & \multirow{2}{*}{$\begin{array}{l}\text { Father's work } \\
\text { hours (weekly) }\end{array}$} & \multirow[b]{2}{*}{$\%$} & \multirow[b]{2}{*}{$\beta$} & \multirow[b]{2}{*}{$P$ value } & \multicolumn{2}{|c|}{$95 \% \mathrm{Cl}$} \\
\hline & & & & Lower & Upper & & & & & Lower & Upper \\
\hline Age 1 year & & & $0.005 \S$ & & & & & & & & \\
\hline Not working & $63 \cdot 1$ & $5 \cdot 58$ & 0.001 & $2 \cdot 37$ & $8 \cdot 79$ & Not working || & $14 \cdot 6$ & 0.96 & $0.47 \S$ & -1.54 & $3 \cdot 35$ \\
\hline $1-15 h$ & $15 \cdot 7$ & $4 \cdot 76$ & 0.01 & $1 \cdot 11$ & $8 \cdot 42$ & Working & $85 \cdot 4$ & ref. & & & \\
\hline $16-24 \mathrm{~h}$ & $10 \cdot 0$ & $5 \cdot 48$ & 0.007 & $1 \cdot 52$ & $9 \cdot 44$ & & & & & & \\
\hline $25-34 \mathrm{~h}$ & $3 \cdot 4$ & 8.90 & 0.001 & $3 \cdot 46$ & $14 \cdot 33$ & & & & & & \\
\hline Age 2 years & & & $0.01 \S$ & & & & & & & & \\
\hline Not working & $65 \cdot 7$ & $5 \cdot 15$ & 0.004 & 1.63 & $8 \cdot 68$ & Not working || & $10 \cdot 9$ & 0.65 & $0.67 \S$ & $2 \cdot 28$ & $3 \cdot 57$ \\
\hline $1-15 h$ & $14 \cdot 6$ & $3 \cdot 12$ & $0 \cdot 13$ & -0.96 & $7 \cdot 20$ & Working & $89 \cdot 1$ & ref. & & & \\
\hline $16-24 \mathrm{~h}$ & $9 \cdot 6$ & 1.55 & 0.49 & $-2 \cdot 84$ & $5 \cdot 95$ & & & & & & \\
\hline $25-34 \mathrm{~h}$ & $2 \cdot 5$ & 1.04 & $0 \cdot 76$ & $-5 \cdot 62$ & $7 \cdot 70$ & & & & & & \\
\hline Age 3 years & & & $<0.001 \S$ & & & & & & & & \\
\hline Not working & $61 \cdot 8$ & $6 \cdot 57$ & $<0.001$ & $3 \cdot 22$ & $9 \cdot 93$ & Not working|| & $9 \cdot 7$ & -0.90 & $0.55 \S$ & $-3 \cdot 89$ & $2 \cdot 09$ \\
\hline $1-15 \mathrm{~h}$ & $15 \cdot 0$ & $4 \cdot 00$ & 0.04 & $0 \cdot 15$ & $7 \cdot 85$ & Working & $90 \cdot 3$ & ref. & & & \\
\hline $16-24 \mathrm{~h}$ & $10 \cdot 4$ & $2 \cdot 94$ & $0 \cdot 17$ & $-1 \cdot 21$ & $7 \cdot 08$ & & & & & & \\
\hline $25-34 \mathrm{~h}$ & $5 \cdot 0$ & $2 \cdot 13$ & 0.41 & $-2 \cdot 88$ & $7 \cdot 15$ & & & & & & \\
\hline Age 5 years & & & $0.07 \S$ & & & & & & $0 \cdot 78 \S$ & & \\
\hline Not working & $49 \cdot 3$ & $3 \cdot 12$ & & $0 \cdot 17$ & $6 \cdot 07$ & Not working & $9 \cdot 5$ & $1 \cdot 17$ & & $-2 \cdot 54$ & $4 \cdot 87$ \\
\hline $1-15 h$ & $15 \cdot 1$ & $3 \cdot 60$ & & $0 \cdot 14$ & $7 \cdot 06$ & $1-34 \mathrm{~h}$ & $5 \cdot 0$ & $1 \cdot 30$ & & $-3 \cdot 44$ & 6.03 \\
\hline $16-24 \mathrm{~h}$ & $15 \cdot 2$ & 0.29 & & $-3 \cdot 18$ & $3 \cdot 75$ & $35-44 \mathrm{~h}$ & $42 \cdot 9$ & -0.51 & & -3.02 & $2 \cdot 01$ \\
\hline $25-34 \mathrm{~h}$ & $8 \cdot \overline{3}$ & 1.51 & & $-2 \cdot 60$ & $5 \cdot 63$ & $45-54 \mathrm{~h}$ & $23 \cdot 4$ & 0.55 & & $-2 \cdot 23$ & $3 \cdot 32$ \\
\hline Age 8 years & & & $0 \cdot 18 \S$ & & & & & & $0.50 \S$ & & \\
\hline Not working & $42 \cdot 8$ & $2 \cdot 93$ & & 0.05 & $5 \cdot 80$ & Not working & $8 \cdot 8$ & $0 \cdot 81$ & & -3.00 & $4 \cdot 60$ \\
\hline $1-15 h$ & $16 \cdot 5$ & $3 \cdot 27$ & & -0.03 & $6 \cdot 58$ & $1-34 \mathrm{~h}$ & $6 \cdot 0$ & $2 \cdot 08$ & & $-2 \cdot 14$ & $6 \cdot 30$ \\
\hline $16-24 \mathrm{~h}$ & $16 \cdot 5$ & 0.92 & & $-2 \cdot 40$ & $4 \cdot 24$ & $35-44 \mathrm{~h}$ & $41 \cdot 8$ & -0.94 & & $-3 \cdot 38$ & $1 \cdot 50$ \\
\hline $25-34 \mathrm{~h}$ & $11 \cdot 1$ & $2 \cdot 52$ & & $-1 \cdot 14$ & $6 \cdot 18$ & $45-54 h$ & $22 \cdot 9$ & $-1 \cdot 01$ & & $-3 \cdot 71$ & $1 \cdot 70$ \\
\hline Age 10 years & & & $0.07 \S$ & & & & & & $0.08 \S$ & & \\
\hline Not working & $30 \cdot 2$ & $1 \cdot 24$ & & $-1 \cdot 64$ & $4 \cdot 13$ & Not working & $6 \cdot 8$ & $3 \cdot 16$ & & $-1 \cdot 24$ & $7 \cdot 57$ \\
\hline $1-15 h$ & $19 \cdot 1$ & $2 \cdot 44$ & & -0.64 & $5 \cdot 52$ & $1-34 \mathrm{~h}$ & $8 \cdot 6$ & 3.98 & & -0.04 & $7 \cdot 93$ \\
\hline $16-24 \mathrm{~h}$ & $18 \cdot 6$ & $1 \cdot 71$ & & $-1 \cdot 36$ & $4 \cdot 78$ & $35-44 h$ & $40 \cdot 4$ & -0.59 & & $-3 \cdot 25$ & $2 \cdot 07$ \\
\hline $25-34 \mathrm{~h}$ & $14 \cdot 9$ & $-1 \cdot 89$ & & $-5 \cdot 14$ & $1 \cdot 36$ & $45-54 h$ & $26 \cdot 9$ & 0.56 & & $-2 \cdot 25$ & $3 \cdot 37$ \\
\hline Age 14 years & & & $0.30 \S$ & & & & & & $0.82 \S$ & & \\
\hline Not working & $22 \cdot 8$ & 0.43 & & $-2 \cdot 34$ & $3 \cdot 20$ & Not working & $7 \cdot 0$ & 0.59 & & $-3 \cdot 85$ & 5.03 \\
\hline $1-15 \mathrm{~h}$ & $15 \cdot 4$ & $2 \cdot 62$ & & -0.37 & $5 \cdot 61$ & $1-34 \mathrm{~h}$ & $8 \cdot 4$ & -1.06 & & $-4 \cdot 81$ & $2 \cdot 70$ \\
\hline $16-24 \mathrm{~h}$ & $18 \cdot 0$ & 1.97 & & -0.81 & $4 \cdot 74$ & $35-44 \mathrm{~h}$ & $42 \cdot 0$ & -0.95 & & -3.49 & 1.59 \\
\hline $25-34 \mathrm{~h}$ & $19 \cdot 2$ & 0.09 & & $-2 \cdot 62$ & $2 \cdot 79$ & $45-54 \mathrm{~h}$ & $24 \cdot 1$ & 0.12 & & -2.63 & $2 \cdot 86$ \\
\hline
\end{tabular}

ref., referent category.

*Separate models were run for each year and all models adjusted for mother's age, education and race, family income at age 14 years, child gender and number of siblings. Mother's and father's/partner's work hours were analysed simultaneously in each model.

tReference group for mother's work hours: $\geq 35 \mathrm{~h}$ weekly.

fDifference in the mean diet quality score between a category of work hours and the reference group. A higher index score represents a better quality diet. $\S P$ value for the global $F$ test for overall differences in diet quality index associated with mother's $(\mathrm{df}=4)$ and father's work hours $(\mathrm{df}=1$ or 4$)$. The $F$ statistic for mother's work hour categories ranged from 1.23 at age 14 years to $5 \cdot 27$ at age 3 years, and for father's work hour categories it ranged from $0 \cdot 19$ at age 2 years to $2 \cdot 11$ at age 10 years.

||Father's work hours were not available at ages 1,2 and 3 years.

TReference group for father's work hours: $\geq 55 \mathrm{~h}$ weekly.

average hours he worked per week had no significant effect on adolescent diet quality at age 14 years.

\section{Discussion}

Our findings suggest that mother's employment status and work hours in the first three to five years of her child's life are linked with diet quality in adolescence. In all families, adolescents whose mothers did not work during the first five years of their life on average had higher diet quality at age 14 years, compared with those whose mothers worked full time during these early years. Similarly, in two-parent families, having a mother staying home at age 1 year to age 3 years, compared with full-time work, was positively associated with an increase in the mean diet quality score at age 14 years. However, this association diminished after age 5 years. This held true regardless of whether we examined the mother's and father's work hours as separate or joint employment variables. Our further analysis aimed at estimating the overall effects demonstrated that maternal full-time work and the average weekly hours a mother worked in the first eight years of her child's life were more strongly associated with a decrease in the diet quality score at age 14 years. Taking all our findings together, it was maternal work hours during early to middle childhood that may have an important impact on adolescent diet quality.

Despite that the age-specific analysis showed a positive association between mother's part-time work at some 
Table 4 Independent association between joint parental work and diet quality at 14 years of age: both-parent families ( $n 1079$ to 1294$)$, the Western Australian Pregnancy Cohort (Raine) Study

\begin{tabular}{|c|c|c|c|c|c|c|c|}
\hline \multirow[b]{3}{*}{ Joint parental work status } & \multicolumn{7}{|c|}{ Diet quality index* } \\
\hline & \multirow[b]{2}{*}{$n$} & \multirow[b]{2}{*}{$\%$} & \multirow[b]{2}{*}{$\beta \dagger$} & \multirow[b]{2}{*}{$P$ value } & \multirow[b]{2}{*}{$F$ test $(\mathrm{df}=4) \ddagger$} & \multicolumn{2}{|c|}{$95 \% \mathrm{Cl}$} \\
\hline & & & & & & Lower & Upper \\
\hline \multicolumn{8}{|l|}{ Age 1 year } \\
\hline Mother PT or FT/father not working & 45 & $3 \cdot 3$ & 3.92 & $0 \cdot 16$ & $P=0.01$ & $-1 \cdot 56$ & $9 \cdot 40$ \\
\hline Neither parent working & 148 & $11 \cdot 0$ & $7 \cdot 32$ & 0.001 & $F=3.60$ & $3 \cdot 18$ & $11 \cdot 47$ \\
\hline Mother PT/father working & 357 & $26 \cdot 6$ & $5 \cdot 98$ & 0.001 & & $2 \cdot 45$ & $9 \cdot 51$ \\
\hline Mother not working/father working & 700 & $52 \cdot 1$ & $5 \cdot 74$ & 0.001 & & $2 \cdot 35$ & $9 \cdot 12$ \\
\hline Mother FT/father working (ref.) & 94 & $7 \cdot 0$ & & & & & \\
\hline \multicolumn{8}{|l|}{ Age 2 years } \\
\hline Mother PT or $\mathrm{FT} /$ father not working & 22 & $2 \cdot 0$ & $-0 \cdot 12$ & 0.98 & $P=0.01$ & $-7 \cdot 75$ & $7 \cdot 51$ \\
\hline Neither parent working & 105 & $9 \cdot 5$ & $6 \cdot 00$ & 0.01 & $F=3 \cdot 17$ & $-1 \cdot 37$ & $10 \cdot 61$ \\
\hline Mother PT/father working & 281 & $25 \cdot 3$ & 1.68 & 0.40 & & $-2 \cdot 20$ & $5 \cdot 56$ \\
\hline Mother not working/father working & 624 & $56 \cdot 2$ & $4 \cdot 35$ & 0.02 & & $0 \cdot 60$ & 8.02 \\
\hline Mother FT/father working (ref.) & 78 & $7 \cdot \overline{0}$ & & & & & \\
\hline \multicolumn{8}{|l|}{ Age 3 years } \\
\hline Mother PT or FT/father not working & 26 & $2 \cdot 1$ & $-1 \cdot 66$ & 0.63 & $P<0.001$ & $-8 \cdot 45$ & $5 \cdot 12$ \\
\hline Neither parent working & 100 & $8 \cdot 1$ & $6 \cdot 72$ & 0.004 & $F=5.68$ & $2 \cdot 11$ & $11 \cdot 33$ \\
\hline Mother PT/father working & 355 & 28.9 & 3.75 & 0.04 & & $0 \cdot 11$ & $7 \cdot 40$ \\
\hline Mother not working/father working & 661 & $53 \cdot 8$ & $6 \cdot 55$ & $<0.001$ & & 3.05 & $10 \cdot 05$ \\
\hline Mother FT/father working (ref.) & 87 & $7 \cdot 1$ & & & & & \\
\hline \multicolumn{8}{|l|}{ Age 5 years } \\
\hline Mother PT or FT/father not working & 38 & $3 \cdot 1$ & $4 \cdot 58$ & & $P=0.17$ & $-1 \cdot 11$ & $10 \cdot 26$ \\
\hline Neither parent working & 76 & $6 \cdot 2$ & $3 \cdot 67$ & & $F=1 \cdot 60$ & -0.97 & $8 \cdot 31$ \\
\hline Mother PT/father working & 453 & $36 \cdot 8$ & $2 \cdot 30$ & & & $-0 \cdot 75$ & $5 \cdot 34$ \\
\hline Mother not working/father working & 529 & $43 \cdot 0$ & 3.59 & & & 0.57 & $6 \cdot 61$ \\
\hline Mother FT/father working (ref.) & 134 & $10 \cdot 9$ & & & & & \\
\hline \multicolumn{8}{|l|}{ Age 8 years } \\
\hline Mother PT or FT/father not working & 40 & $3 \cdot 3$ & $2 \cdot 88$ & & $P=0.26$ & $-2 \cdot 62$ & $8 \cdot 37$ \\
\hline Neither parent working & 62 & $5 \cdot 1$ & $4 \cdot 69$ & & $F=1 \cdot 33$ & $-0 \cdot 10$ & $9 \cdot 47$ \\
\hline Mother PT/father working & 511 & $42 \cdot 0$ & $2 \cdot 72$ & & & $-0 \cdot 15$ & $5 \cdot 60$ \\
\hline Mother not working/father working & 458 & $37 \cdot 6$ & 2.96 & & & 0.04 & $5 \cdot 89$ \\
\hline Mother FT/father working (ref.) & 146 & $12 \cdot 0$ & & & & & \\
\hline \multicolumn{8}{|l|}{ Age 10 years } \\
\hline Mother PT or $\mathrm{FT} /$ father not working & 39 & $3 \cdot 2$ & 0.96 & & $P=0.58$ & $-4 \cdot 78$ & $6 \cdot 71$ \\
\hline Neither parent working & 41 & $3 \cdot 4$ & $4 \cdot 83$ & & $F=0.72$ & $-0 \cdot 84$ & $10 \cdot 50$ \\
\hline Mother PT/father working & 617 & $51 \cdot 1$ & 0.77 & & & $-1 \cdot 87$ & 3.40 \\
\hline Mother not working/father working & 322 & $26 \cdot 7$ & 0.62 & & & $-2 \cdot 32$ & 3.57 \\
\hline Mother FT/father working (ref.) & 188 & $15 \cdot 6$ & & & & & \\
\hline \multicolumn{8}{|l|}{ Age 14 years } \\
\hline Mother PT or FT/father not working & 50 & $4 \cdot 0$ & $-2 \cdot 84$ & $0 \cdot 28$ & $P=0.02$ & $-7 \cdot 94$ & $2 \cdot 26$ \\
\hline Neither parent working & 38 & 3.0 & $7 \cdot 80$ & 0.02 & $F=3.03$ & 1.54 & 14.05 \\
\hline Mother PT/father working & 638 & $50 \cdot 9$ & $1 \cdot 44$ & 0.21 & & -0.81 & $3 \cdot 70$ \\
\hline Mother not working/father working & 247 & $19 \cdot 7$ & -0.60 & 0.68 & & $-3 \cdot 45$ & $2 \cdot 25$ \\
\hline Mother FT/father working (ref.) & 280 & $22 \cdot 3$ & & & & & \\
\hline
\end{tabular}

PT, part time; FT, full time; ref., referent category.

*All models adjusted for mother's age, education and race, family income at age 14 years, child gender and number of siblings.

tDifference in the mean diet quality score between a category of work hours and the reference group. A higher index score represents a better quality diet. $\ddagger$ Test statistics for overall differences in diet quality index associated with joint work status.

follow-ups and diet quality at age 14 years, the analysis of the overall effects of part-time employment on the outcome variable showed no statistical significance.

In contrast to the results found with the mother staying at home, father's employment status or work hours was not significantly associated with adolescent diet quality. The results from the analysis of joint employment showed no significant difference in child diet quality when the father stayed at home while the mother was working either part time or full time. This finding is consistent with previous research that mothers are mainly responsible for household work, including meal provision, even when they participate in the labour force $\mathrm{e}^{(2,28,29)}$.
Our study has shown that when neither the mother nor the father worked when the child was 1 to 3 years of age, the diet quality in adolescence was higher than when both parents worked during these years. It is plausible that when no parent works, the mother has more time to plan and prepare healthy meals for the family especially if the father assists with child care and other housework.

The presence of a second child in the family was found to be associated with a decrease in the average diet quality score in the age-specific analyses that included both-parent families only and also in analysis of cumulative effects of mothers working full time on adolescent diet quality at 
Table 5 Overall association between parental working hours since child's birth and diet quality at 14 years of age $(n=876-1016)^{\star}$, the Western Australian Pregnancy Cohort (Raine) Study

\begin{tabular}{|c|c|c|c|c|c|}
\hline & \multicolumn{5}{|c|}{ Diet quality index } \\
\hline & \multirow[b]{2}{*}{ Mean } & \multirow[b]{2}{*}{$\beta \dagger$} & \multirow[b]{2}{*}{$P$ value } & \multicolumn{2}{|c|}{$95 \% \mathrm{Cl}$} \\
\hline & & & & Lower & Upper \\
\hline \multicolumn{6}{|l|}{ Mother's work hours } \\
\hline \multicolumn{6}{|l|}{ Average hours worked weekly } \\
\hline First three years & $6 \cdot 7$ & $-0 \cdot 21$ & $<0.001$ & -0.31 & $-0 \cdot 12$ \\
\hline First five years & $7 \cdot 8$ & $-0 \cdot 22$ & $<0.001$ & -0.32 & $-0 \cdot 13$ \\
\hline First eight years & $8 \cdot 7$ & $-0 \cdot 20$ & $<0.001$ & $-0 \cdot 30$ & -0.09 \\
\hline First ten years & $10 \cdot 0$ & $-0 \cdot 18$ & 0.001 & -0.29 & -0.07 \\
\hline From age 1 year to age 14 years & $11 \cdot 6$ & $-0 \cdot 17$ & 0.003 & -0.027 & -0.07 \\
\hline \multicolumn{6}{|l|}{ Number of years worked full time } \\
\hline First three years & $0 \cdot 2$ & $-2 \cdot 94$ & $<0.001$ & $-4 \cdot 41$ & $-1 \cdot 46$ \\
\hline First five years & $0 \cdot 3$ & $-2 \cdot 15$ & $<0.001$ & $-3 \cdot 16$ & -0.95 \\
\hline First eight years & $0 \cdot 4$ & $-1 \cdot 45$ & 0.006 & $-2 \cdot 49$ & -0.42 \\
\hline First ten years & $0 \cdot 6$ & $-0 \cdot 82$ & 0.07 & $-1 \cdot 70$ & -0.06 \\
\hline From age 1 year to age 14 years & $0 \cdot 8$ & $-0 \cdot 82$ & 0.03 & $-1 \cdot 56$ & -0.08 \\
\hline \multicolumn{6}{|l|}{ Number of years worked part time } \\
\hline First three years & $0 \cdot 8$ & -0.75 & $0 \cdot 10$ & $-1 \cdot 64$ & $-0 \cdot 13$ \\
\hline First five years & $1 \cdot 2$ & -0.62 & 0.09 & $-1 \cdot 35$ & $-0 \cdot 11$ \\
\hline First eight years & $1 \cdot \overline{6}$ & -0.52 & $0 \cdot 10$ & $-1 \cdot 15$ & $-0 \cdot 10$ \\
\hline First ten years & $2 \cdot 2$ & -0.55 & 0.06 & $-1 \cdot 11$ & -0.01 \\
\hline From age 1 year to age 14 years & $2 \cdot 7$ & -0.26 & 0.33 & $-0 \cdot 77$ & 0.26 \\
\hline \multicolumn{6}{|l|}{ Father's work hours } \\
\hline Number of years worked $\geq 45 \mathrm{~h}$ weekly (from ages 5 to 14 years) & $1 \cdot 8$ & 0.29 & 0.49 & -0.48 & 0.99 \\
\hline Average hours worked weekly from ages 5 to 14 years & $42 \cdot 3$ & -0.03 & 0.53 & $-0 \cdot 12$ & 0.06 \\
\hline
\end{tabular}

*All multivariate models were based on cases with no missing data at each respective follow-up point, included all families and adjusted for mother's age, education and race, family income and family structure at age 14 years, child gender and number of siblings. Mother's education at age 8 years was adjusted for at ages 8,10 and 14 years.

tChange in the mean diet quality score with an increment in average hours or years worked. A higher index score represents a better quality diet.

age 14 years: the magnitude of effect ranged from $b=-1 \cdot 92$ to $b=-3 \cdot 14(P=0 \cdot 052$ to $P=0 \cdot 006)$. However, the adjustment of this factor did not alter the effect of mother's and father's work hours on the outcome variable.

Previous studies, mostly cross-sectional in nature, have reported conflicting results about associations between maternal employment and adolescent diet quality ${ }^{(8,11,30-34)}$. By examining the relationship between parental employment status and weekly working hours prospectively, our age-specific analysis has revealed that having mothers stay home in the first three to five years of life was beneficial to their child's diet quality in adolescence. Based on our observations, healthy eating in children begins early in life and takes time to develop. This may be because children need to develop a taste early for healthy food and learn to conform to parental preferences and requirements for healthy eating habits. Once a pattern of healthy diet is established in the family, it may well continue through to adolescence and adulthood. It may require parental time and energy to develop healthy eating patterns early and to maintain them through childhood. Our study has relevance for future research on maternal work and other health-related behaviours which may also begin early in life and develop over time, including physical activity and risk-taking behaviours.

\section{Strengths and limitations}

The present study has several strengths. It is a prospective study of parental work and adolescent diet quality using longitudinal information on the predictor measured at various ages of a child's development, with a large cohort size. It systematically examined the possible effect of father's employment status and work hours on adolescent diet quality. The study adjusted for important confounders. However, the study also has some limitations. Due to the lack of information on child diet prior to age 14 years we were unable to investigate whether or not and to what extent diet quality in early and mid childhood is associated with diet quality in adolescence. This link would facilitate a better understanding of our finding that maternal work hours in early to middle childhood but not at later ages influence adolescent diet quality at age 14 years. Further, while our measure of diet quality was based on the dietary intake jointly reported by the primary caregiver and the adolescent, it would be important for future research in this field to utilize self-reported dietary intake by adolescents themselves.

\section{Policy implications}

The percentage of working women with children under 5 years of age has increased over the last two decades ${ }^{(1)}$. Given the benefit of having a mother stay at home in early to middle childhood for later adolescent diet quality, support is needed for families where the mother returns to full-time employment before the child reaches 8 years of age. Implementation of healthy eating guidelines and provision of healthy food at child-care centres, pre-schools 
and schools are one way of helping children of working mothers develop healthy eating habits early. Governmental incentives for food industries to be innovative in producing healthy food products that are affordable, meet nutritional requirements but require less time to prepare would be another way of supporting working mothers, fathers and their children.

\section{Acknowledgements}

Sources of funding: The Raine Study is supported by the National Health and Medical Research Council (NH\&MRC) of Australia and the Telethon Institute for Child Health Research. Funding for Core Management of the Raine Study is provided by the University of Western Australia (UWA), the Telethon Institute for Child Health Research, the Raine Medical Research Foundation, the UWA Faculty of Medicine, Dentistry and Health Sciences, and the Women and Infants Research Foundation. J.L. is supported by the Curtin University Research Fellowship Scheme and the NH\&MRC Program Grant (\#572742). W.O. was supported by an NH\&MRC Career Development Award. T.O. was supported by the Heart Foundation Beyond Blue Strategic Research Initiative. S.J. is supported by a research grant from the Foundation for Children. Conflict of interest declaration: The authors declare that they have no conflict of interest. Authors' contributions: J.L. was responsible for the conception, analysis and the writing of the manuscript. T.O. contributed to the review of the literature and the interpretation of the findings. W.O. was responsible for developing the diet quality index and contributed to the interpretation of the results. S.J. contributed to the analysis, the review of the literature and the interpretation of the results. F.S. contributed to the study design and the interpretation of the results. All authors provided substantive comments on various drafts of the manuscript. Acknowledgements: The authors gratefully acknowledge the Raine Study participants and their families for their participation in the study; the Raine Study Team for cohort co-ordination and data collection.

\section{References}

1. Hayes A, Weston R, Qu L et al. (2010) Families Then and Now, 1980-2010 (Factsheet). Melbourne: Australian Institute of Family Studies; available at http://www.aifs.gov.au/ institute/pubs/factsheet/fs2010conf/fs2010conf.pdf

2. Lake AA, Hyland RM, Mathers JC et al. (2006) Food shopping and preparation among the 30-somethings: whose job is it? (The ASH30 study). Br Food J 108, 475-486.

3. Soyer M, Ergin I \& Gursoy S (2008) Effects of social determinants on food choice and skipping meals among Turkish adolescents. Asia Pac J Clin Nutr 17, 208-215.

4. Tucker K \& Sanjur D (1988) Maternal employment and child nutrition in Panama. Soc Sci Med 26, 605-612.

5. Hawkins S, Cole $T$ \& Law C (2009) Examining the relationship between maternal employment and health behaviours in 5-year-old British children. I Epidemiol Community Health 63, 999-1004.

6. Neumark-Sztainer D, Hannan PJ, Story M et al. (2003) Family meal patterns: associations with sociodemographic characteristics and improved dietary intake among adolescents. J Am Diet Assoc 103, 317-322.

7. Johnson RK, Smiciklas-Wright H, Crouter AC et al. (1992) Maternal employment and the quality of young children's diets: empirical evidence based on the 1987-1988 Nationwide Food Consumption Survey. Pediatrics 90, 245-249.

8. Siega-Riz AM, Carson T \& Popkin B (1998) Three squares or mostly snacks - what do teens really eat?: a sociodemographic study of meal patterns. J Adolesc Health 22, 29-36.

9. Baghurst KI \& Record SJ (1983) Intake and sources in selected Australian subpopulations of dietary constituents implicated in the etiology of chronic diseases. J Food Nutr 40, 1-15.

10. Baghurst KI \& Record SJ (1984) A computerised dietary analysis system for use with diaries or food frequency questionnaires. Community Health Stud 8, 11-18.

11. Fertig A, Glomm G \& Tchernis R (2009) The connection between maternal employment and childhood obesity: inspecting the mechanisms. Rev Econ Houseb 7, 227-255.

12. Sweeting H \& West P (2005) Dietary habits and children's family lives. J Hum Nutr Diet 18, 93-97.

13. Lindholm BW, Touliatos J \& Wenberg MF (1984) Predicting changes in nutrition knowledge and dietary quality in tento thirteen-year-olds following a nutrition education program. Adolescence 19, 367-375.

14. Johansen A, Rasmussen S \& Madsen M (2006) Health behaviour among adolescents in Denmark: influence of school class and individual risk factors. Scand J Public Health 34, 32-40.

15. Hu FB (2002) Dietary pattern analysis: a new direction in nutritional epidemiology. Curr Opin Lipidol 13, 3-9.

16. Bauer KW, Larson NI, Nelson MC et al. (2009) Socioenvironmental, personal and behavioural predictors of fastfood intake among adolescents. Public Health Nutr 12, $1767-1774$.

17. Newnham JP, Evans SF, Michael CA et al. (1993) Effects of frequent ultrasound during pregnancy: a randomised controlled trial. Lancet 342, 887-891.

18. Ambrosini GL, de Klerk NH, O'Sullivan TA et al. (2009) The reliability of a food frequency questionnaire for use among adolescents. Eur J Clin Nutr 63, 1251-1259.

19. Smith A, Kellett E \& Schmerlaib Y (1998) The Australian Guide to Healthy Eating. Canberra: Commonwealth of Australia.

20. National Health and Medical Research Council (2006) Nutrient Reference Values for Australia and New Zealand. Canberra: Commonwealth of Australia.

21. Videon TM \& Manning CK (2003) Influences on adolescent eating patterns: the importance of family meals. $J$ Adolesc Health 32, 365-373.

22. North K \& Emmett P (2000) Multivariate analysis of diet among three-year-old children and associations with sociodemographic characteristics. Eur J Clin Nutr 54, 73-80.

23. Giskes K, van Lenthe F, Brug HJ et al. (2004) Dietary intakes of adults in the Netherlands by childhood and adulthood socioeconomic position. Eur J Clin Nutr 58, 871-880.

24. Mullie P, Clarys P, Ridder DD et al. (2006) Breakfast frequency and fruit and vegetable consumption in Belgian adolescents. A cross-sectional study. Nutr Food Sci 36, 315-326.

25. Milligan RAK, Burke V, Beilin LJ et al. (1998) Influence of gender and socio-economic status on dietary patterns and nutrient intakes in 18-year-old Australians. Aust $N Z J$ Public Health 22, 485-493.

26. Giskes KK, Turrell GG, Patterson CC et al. (2002) Socioeconomic differences in fruit and vegetable consumption 
among Australian adolescents and adults. Public Health Nutr 5, 663-669.

27. Kranz S (2006) Meeting the dietary reference intakes for fiber: sociodemographic characteristics of preschoolers with high fiber intakes. Am J Public Health 96, 1538-1541.

28. Backman D, Haddad E, Lee J et al. (2002) Psychosocial predictors of healthful dietary behavior in adolescents. J Nutr Educ Behav 34, 184-192.

29. Bond S \& Sales J (2001) Household work in the UK: an analysis of the British Household Panel Survey 1994. Work Employ Soc 15, 233-250.

30. French SA (2001) Fast food restaurant use among adolescents: associations with nutrient intake, food choices and behavioral and psychosocial variables. Int J Obes Relat Metab Disord 25, 1823-1833.
31. Johansen A, Rasmussen S \& Madsen M (2006) Health behaviour among adolescents in Denmark: influence of school class and individual risk factors. Scand J Public Health 34, 32-40.

32. Larson NI, Story M, Eisenberg ME et al. (2006) Food preparation and purchasing roles among adolescents: associations with sociodemographic characteristics and diet quality. J Am Diet Assoc 106, 211-218.

33. Skinner JD, Ezell JM, Salvetti NN et al. (1985) Relationships between mothers' employment and nutritional quality of adolescents' diets. Fam Consum Sci Res J 13, 218-225.

34. Würbach A, Zellner K \& Kromeyer-Hauschild K (2009) Meal patterns among children and adolescents and their associations with weight status and parental characteristics. Public Health Nutr 12, 1115-1121. 